\title{
SPESIASI DAN BIOAVAILABILITAS Pb DAN Cu DALAM TANAH PERTANIAN ORGANIK DI BEDUGUL SERTA KANDUNGAN LOGAM TOTALNYA DALAM SAYUR BROKOLI
}

\author{
I M. Siaka*, H. Nurcahyani dan I B. P. Manuaba \\ Progam Studi Kimia Fakultas Matematika dan Ilmu Pengetahuan Alam Universitas Udayana \\ Jalan Kampus Unud-Jimbaran, Jimbaran-Bali, Indonesia \\ *e-mail:made_siaka@unud.ac.id
}

\begin{abstract}
ABSTRAK
Daerah Bedugul adalah sentra penghasil sayur mayur di Bali yang juga mengembangkan pertanian organik. Penelitian ini bertujuan untuk mengetahui bioavailabilitas $\mathrm{Pb}$ dan $\mathrm{Cu}$ dalam tanah pertanian organik di Bedugul serta kandungan kedua logam dalam sayur brokoli sebelum penanaman dan saat panen. Ekstraksi logam dilakukan melalui digesti basah dan bioavailabilitasnya ditentuksn melalui metode ekstraksi bertahap. Pengukuran kedua logam dilakukan dengan menggunakan AAS. Kandungan $\mathrm{Pb}$ total dalam tanah pertanian organik sebelum penanaman dan saat panen berturut-turut 746,1042-897,3754 mg/kg dan 277,7876-328,8217 $\mathrm{mg} / \mathrm{kg}$, sedangkan untuk Cu sebesar 93,1281-114,3259 mg/kg, dan 48,6088-92,3708 mg/kg. Bioavailabilitas Pb dan $\mathrm{Cu}$ dalam tanah pertanian organik sebelum penanaman berbeda dengan tanah pertanian organik saat panen. Logam $\mathrm{Pb}$ dalam tanah pertanian organik sebelum penanaman yang serta merta bioavailabel, berpotensi bioavailabel, dan nonbioavailabel berturut-turut $(17,80-21,62) \%$, $(44,07-47,65) \%$, dan $(30,73-36,89) \%$, sedangkan untuk $\mathrm{Cu}(5,02-7,89) \%$, $(55,73-60,57) \%$, dan $(32,81-39,25) \%$. Kandungan $\mathrm{Pb}$ dan $\mathrm{Cu}$ total dalam sayur brokoli sebesar $(27,2968-30,3621) \mathrm{mg} / \mathrm{kg}$ dan $(27,0303-30,0223) \mathrm{mg} / \mathrm{kg}$.
\end{abstract}

Kata kunci: bioavailabilitas, brokoli, $\mathrm{Pb}$ dan $\mathrm{Cu}$, spesiasi, tanah pertanian organik

\begin{abstract}
Bedugul area is a vegetable producing center in Bali that also develops organic farming. This study aimed to determine the bioavailability of $\mathrm{Pb}$ and $\mathrm{Cu}$ in an organic farm in Bedugul and the content of both metals in broccoli before planting and at harvest. Metal extraction was carried out through wet digestion and its bioavailability was determined by the application of the sequential extraction methods. The measurement of the two metals was accomplished by using AAS. The total $\mathrm{Pb}$ content in the organic soils before and after harvesting were found to be $746.102-897.3754 \mathrm{mg} / \mathrm{kg}$ and $277.778-328.88217 \mathrm{mg} / \mathrm{kg}$, while $\mathrm{Cu}$ were of $93.1212-11$ $114.3259 \mathrm{mg} / \mathrm{kg}$, and $48,608-92.3708 \mathrm{mg} / \mathrm{kg}$, respectively. The bioavailability of $\mathrm{Pb}$ and $\mathrm{Cu}$ in soils before planting was different from that of at harvest. $\mathrm{Pb}$ metal in organic soil before planting which were readily bioavailable, bioavailable, and nonbioavailable were were found to be $(17.80-21.62) \%$, (44.07-47.65)\%, and (30.73-36, 89$) \%$, while $\mathrm{Cu}$ were of $(5.02-7.89) \%,(55.73-60.57) \%$, and $(32.81-39.25) \%$, respectively. The total $\mathrm{Pb}$ and $\mathrm{Cu}$ contents in broccoli were of $(27,2968-30,3621) \mathrm{mg} / \mathrm{kg}$ and $(27,0303-30,0223) \mathrm{mg} / \mathrm{kg}$, respectively.
\end{abstract}

Keywords: bioavailability, broccoli, organic agriculture soil, $\mathrm{Pb}$ and $\mathrm{Cu}$, speciation

\section{PENDAHULUAN}

Sayur brokoli dengan nilai ekonomis yang cukup tinggi dijadikan salah satu sayuran yang dibudidayakan oleh para petani di daerah Bedugul, baik dari tanah pertanian anorganik maupun organik. Hasil produksi dari tanah pertanian organik biasanya dianggap lebih baik dibandingkan dengan tanah pertanian anorganik, karena pupuk dan pestisida yang digunakan berasal dari sisa-sisa makhluk hidup yang diolah melalui proses pembusukan/dekomposisi oleh bakteri pengurai. Kenyataannya tanah pertanian organik mengandung logam berat yang cukup tinggi yang berasal dari pupuk organik yang digunakan. Menurut Alloway (1990) pupuk kompos dan kandang mengandung $\mathrm{Pb}$ dan $\mathrm{Cu}$ berturut-turut sebesar $1,3-2.240 \mathrm{mg} / \mathrm{kg}$ dan $13-$ $3.580 \mathrm{mg} / \mathrm{kg}$ dan $30-969 \mathrm{mg} / \mathrm{kg}$ dan $2-172$ $\mathrm{mg} / \mathrm{kg}$. Tanah pertanian yang tercemar logam berat dapat mempengaruhi tanaman yang tumbuh di tanah pertanian tersebut. Logam berat akan masuk ke dalam jaringan tanaman 
melalui akar dan daun, dan akan masuk ke dalam siklus rantai makanan (Widowati dkk, 2008). Penyerapan logam berat oleh tanaman sangat bergantung pada spesies dan bioavailabilitas logam berat tersebut di dalam tanah. Bioavailabilitas merupakan ketersediaan sejumlah logam yang diserap oleh hayati (organisme dan tumbuhan) yang dapat menyebabkan respon toksik. (Widaningrum dkk, 2007).

Pada dasarnya, spesiasi logam berat dalam tanah adalah fraksinasi dari kandungan logam total menjadi dalam bentuk dapat dipertukarkan (terikat dengan mineral-mineral tanah liat), bentuk terekstraksi asam (terikat dengan karbonat dan hidroksida), bentuk dapat direduksi (terikat dengan $\mathrm{Fe} / \mathrm{Mn}$ oksida), bentuk teroksidasi (terikat bahan organik/sulfida), dan bentuk residu yang terikat dalam mineral seperti silikat. Bentukbentuk seperti ini dapat bersifat bioavailable, berpotensi bioavailable, dan non bioavailable. Logam yang langsung bioavailable terdapat dalam bentuk exchangeable dan terekstraksi asam, logam yang berpotensi bioavailable dalam bentuk reducible dan oxidizable, dan yang non-bioavailable terdapat dalam bentuk residu yang terikat dalam silikat atau mineral (Oluremi et al., 2013).

Berdasarkan penelitian Tri Rahayu (2015) menyatakan konsentrasi rata-rata $\mathrm{Cu}$ total dalam tanah pertanian organik berusia 4 dan 5 tahun berkisar antara 41,8808-49,1060 mg/kg dan 22,8544-41,6616 $\mathrm{mg} / \mathrm{kg}$ yang sudah dikategorikan pada tingkat pencemaran sedang, yaitu $25-75 \mathrm{mg} / \mathrm{kg}$. Oleh karena itu, pencemaran pada tanah pertanian organik perlu diteliti agar mengetahui tanaman yang tumbuh diatas tanah pertanian tersebut tercemar atau tidak, serta perlu dilakukan analisis fase kimia (spesies-spesies) logam berat tersebut untuk menentukan mobilitasnya sehingga dapat diketahui bioavailabilitasnya.

\section{MATERI DAN METODE}

\section{Bahan}

Bahan-bahan yang digunakan pada penelitian ini adalah sampel tanah dari lahan pertanian organik dan sayur brokoli di daerah Bedugul, $\mathrm{HCl}$ (p.a), $\mathrm{HNO}_{3}$ (p.a), $\mathrm{Pb}\left(\mathrm{NO}_{3}\right)_{2}$, $\mathrm{CuSO}_{4} .5 \mathrm{H}_{2} \mathrm{O}, \quad \mathrm{CH}_{3} \mathrm{COONH}_{4}, \quad \mathrm{NH}_{2} \mathrm{OH} . \mathrm{HCl}$, $\mathrm{CH}_{3} \mathrm{COOH}$ (p.a), $\mathrm{H}_{2} \mathrm{O}_{2}$, dan aquades.

\section{Peralatan}

Alat-alat yang digunakan dalam penelitian ini adalah labu ukur, gelas ukur, gelas beaker, pipet volume, pipet tetes, mortar, oven, neraca analitik, erlenmeyer, corong, kertas saring, botol semprot, ayakan $63 \mu \mathrm{m}$, sendok plastik, kantong plastik, botol plastik, penangas air, hotplate, sentrifugasi, $\mathrm{pH}$ meter, thermometer, mesin penggojog (shaker), ultrasonic bath dan Spektrofotometer Serapan Atom (AAS).

\section{Tempat Penelitian}

Penelitian ini dilakukan di Laboratorium FTP Universitas Udayana, Laboratorium Penelitian Program Studi Kimia FMIPA Universitas Udayana, dan Laboratorium Bersama FMIPA Universitas Udayana.

\section{CARA KERJA}

\section{Preparasi \\ Preparasi sampel tanah}

Sampel tanah dikeringkan dalam oven pada suhu $60^{\circ} \mathrm{C}$ hingga massa konstan. Sampel tanah yang telah kering digerus dengan mortar hingga halus, diayak dengan ayakan $63 \mu \mathrm{m}$, dan disimpan dalam botol untuk analisis lebih lanjut.

\section{Preparasi sampel sayur brokoli}

Sampel sayur brokoli dicuci dengan aquades, dipotong kecil, dan dikeringkan dalam oven pada suhu $60^{\circ} \mathrm{C}$ hingga massa konstan. Sampel yang telah kering digerus dengan mortar hingga halus, diayak dengan ayakan $63 \mu \mathrm{m}$, dan disimpan dalam botol untuk analisis lebih lanjut.

\section{Penentuan konsentrasi logam $\mathrm{Pb}$ dan $\mathrm{Cu}$ total dalam tanah}

Sebanyak 1 gram sampel tanah dimasukkan ke dalam gelas beaker, dan ditambahkan $10 \mathrm{~mL}$ larutan reverse aquaregia yaitu campuran $\mathrm{HCl}$ pekat dan $\mathrm{HNO}_{3}$ (1:3). Kemudian campuran didigesti dengan ultrasonic bath pada suhu $60^{\circ} \mathrm{C}$ selama 45 menit dan dipanaskan pada hotplate pada suhu $140^{\circ} \mathrm{C}$ selama 45 menit. Larutan yang diperoleh disaring, filtratnya ditampung dan 
diencerkan dengan aquades dalam labu ukur $50 \mathrm{~mL}$ sampai tanda batas. Larutan tersebut diukur dengan Spektrofotometer Serapan Atom (AAS) pada panjang gelombang 217,0 $\mathrm{nm}$ untuk $\mathrm{Pb}$ dan $324,7 \mathrm{~nm}$ untuk $\mathrm{Cu}$.

\section{Penentuan konsentrasi logam $\mathrm{Pb}$ dan $\mathrm{Cu}$ total dalam brokoli}

Sebanyak 1 gram sampel sayur brokoli dimasukkan ke dalam gelas beaker, dan ditambahkan $10 \mathrm{~mL}$ larutan reverse aquaregia yaitu campuran $\mathrm{HCl}$ pekat dan $\mathrm{HNO}_{3}$ pekat (1:3). Kemudian campuran didigesti dengan ultrasonic bath pada suhu $60^{\circ} \mathrm{C}$ selama 45 menit dan dipanaskan pada hotplate pada suhu $140^{\circ} \mathrm{C}$ selama 45 menit. Larutan hasil digesti disentrifugasi hingga diperoleh supernatant. Supernatant yang diperoleh ditampung dan diencerkan dengan aquades dalam labu ukur $50 \mathrm{~mL}$ sampai tanda batas. Larutan tersebut diukur dengan Spektrofotometer Serapan Atom (AAS) pada panjang gelombang 217,0 $\mathrm{nm}$ untuk $\mathrm{Pb}$ dan $324,7 \mathrm{~nm}$ untuk $\mathrm{Cu}$ (Siaka et al., 2006).

\section{Ekstraksi Bertahap}

Prosedur penelitian ekstraksi bertahap didasarkan atas metode yang diusulkan oleh Davidson et al. (1998)

Ekstraksi Tahap I (Fraksi Easly, Freely, Leachable, and Exchangeable)

Sebanyak 1 gram sampel tanah ditambahkan $40 \mathrm{~mL} \mathrm{CH}_{3} \mathrm{COOH} 0,1 \mathrm{M}$, lalu digojog selama 2 jam, dan disentrifugasi selama 10 menit dengan kecepatan $400 \mathrm{rpm}$. Filtrat yang diperoleh dimasukkan ke dalam labu ukur $50 \mathrm{~mL}$ dan diencerkan dengan aquades sampai tanda batas, kemudian diukur dengan Spektrofotometer Serapan Atom (AAS) pada panjang gelombang 217,0 $\mathrm{nm}$ untuk $\mathrm{Pb}$ dan 324,7 nm untuk $\mathrm{Cu}$. Residu yang diperoleh digunakan untuk ekstraksi tahap selanjutnya.

\section{Ekstraksi Tahap II (Fraksi Mn dan Fe Oksida)}

Residu fraksi I ditambahkan $40 \mathrm{~mL}$ $\mathrm{NH}_{2} \mathrm{OH} . \mathrm{HCl}$ 0,1 $\mathrm{M}$ dan tingkat keasaman diatur pada $\mathrm{pH} 2$ dengan menambahkan $\left(\mathrm{HNO}_{3}\right)$. Campuran digojog selama 2 jam, dan disentrifugasi selama 10 menit dengan kecepatan $400 \mathrm{rpm}$. Filtrat yang diperoleh dimasukkan ke dalam labu ukur $50 \mathrm{~mL}$ dan diencerkan dengan aquades sampai tanda batas, kemudian diukur dengan Spektrofotometer Serapan Atom (AAS) pada panjang gelombang 217,0 nm untuk $\mathrm{Pb}$ dan 324,7 nm untuk $\mathrm{Cu}$. Residu yang diperoleh digunakan untuk ekstraksi tahap selanjutnya.

\section{Ekstraksi Tahap III (Fraksi Organik dan Sulfida)}

Residu fraksi II ditambahkan $10 \mathrm{~mL}$ larutan $\mathrm{H}_{2} \mathrm{O}_{2} \quad 8,8 \quad \mathrm{M}$ kemudian didiamkan selama 1 jam pada suhu ruang dan dikocok sesekali. Selanjutnya campuran dipanaskan pada suhu $85^{\circ} \mathrm{C}$ selama 1 jam dalam penangas air. Campuran ditambah $10 \mathrm{~mL}$ larutan $\mathrm{H}_{2} \mathrm{O}_{2}$ $8,8 \mathrm{M}$ dan dipanaskan kembali pada suhu $85^{\circ} \mathrm{C}$ selama 1 jam. Selanjutnya campuran didinginkan dan ditambahkan $20 \mathrm{~mL}$ $\mathrm{CH}_{3} \mathrm{COONH}_{4} 1 \mathrm{M}$, dan ditambahkan $\mathrm{HNO}_{3}$ untuk mengatur tingkat keasaman pada $\mathrm{pH} 2$. Campuran digojog selama 2 jam dan disentrifugasi selama 10 menit dengan kecepatan $400 \mathrm{rpm}$. Supernatan yang diperoleh dimasukkan ke dalam labu ukur $50 \mathrm{~mL}$ dan diencerkan dengan aquades sampai tanda batas, kemudian diukur dengan Spektrofotometer Serapan Atom (AAS) pada panjang gelombang 217,0 $\mathrm{nm}$ untuk $\mathrm{Pb}$ dan 324,7 nm untuk $\mathrm{Cu}$. Residu yang diperoleh digunakan untuk ekstraksi tahap selanjutnya.

\section{Ekstraksi Tahap IV (Fraksi Resistant)}

Residu fraksi III dicuci dengan $10 \mathrm{~mL}$ aquades dan ditambahkan $10 \mathrm{~mL}$ campuran $\mathrm{HNO}_{3}$ pekat dan $\mathrm{HCl}$ pekat (3:1). Campuran sampel didigesti dengan ultrasonic bath pada suhu $60^{\circ} \mathrm{C}$ selama 45 menit dan dipanaskan pada hotplate pada suhu $140^{\circ} \mathrm{C}$ selama 45 menit. Selanjutnya campuran disentrifugasi selama 10 menit dengan kecepatan $400 \mathrm{rpm}$. Supernatant yang diperoleh dimasukkan ke dalam labu ukur $50 \mathrm{~mL}$ dan diencerkan dengan aquades sampai tanda batas, kemudian diukur dengan Spektrofotometer Serapan Atom (AAS) pada panjang gelombang 217,0 $\mathrm{nm}$ untuk $\mathrm{Pb}$ dan $324,7 \mathrm{~nm}$ untuk $\mathrm{Cu}$. 


\section{HASIL DAN PEMBAHASAN}

\section{Konsentrasi Pb dan $\mathrm{Cu}$ Total Dalam Sampel Tanah Pertanian Organik}

Penentuan konsentrasi $\mathrm{Pb}$ dan $\mathrm{Cu}$ total dalam sampel tanah pertanian organik dilakukan dengan metode kurva kalibrasi. Persamaan regresi linier dari kurva kalibrasi logam $\mathrm{Pb}$ yaitu $\mathrm{y}=0,0402 \mathrm{x}+0,0019$ dengan koefisien regresi $(R) 0,9998$ dan untuk logam $\mathrm{Cu}$ y $=0,1896 \mathrm{x}+0,0077$ dengan koefisien regresi $(R)$ 0,9996. Hasil koefisien regresi $(R)$ logam $\mathrm{Pb}$ dan $\mathrm{Cu}$ yang diperoleh memberikan linearitas kurva kalibrasi yang baik dan dinyatakan valid karena memiliki nilai $R \geq$ 0,9970 (Chan et al., 2004). Persamaan regresi linier dari kedua logam tersebut digunakan untuk menentukan konsentrasi logam $\mathrm{Pb}$ dan $\mathrm{Cu}$ total dalam sampel tanah pertanian organik dan sayur brokoli. Kandungan total logam $\mathrm{Pb}$ dan $\mathrm{Cu}$ dalam tanah pertanian organik sebelum penanaman secara berturut-turut adalah $746,1042-897,3754 \mathrm{mg} / \mathrm{kg}$ dan 93,1281$114,3259 \mathrm{mg} / \mathrm{kg}$, dan $277,7876-328,8217$ $\mathrm{mg} / \mathrm{kg}$ dan 48,6088-92,3708 mg/kg dalam tanah pertanian organik saat panen. Hasil tersebut menunjukkan kandungan logam $\mathrm{Pb}$ total dalam tanah dari ketiga lahan pertanian organik sebelum penanaman dikategorikan agak tercemar, yaitu $500-1000 \mathrm{mg} / \mathrm{kg}$, sedangkan tanah saat panen masih dalam batas yang diperbolehkan, yaitu $0-500 \mathrm{mg} / \mathrm{kg}$ (Alloway, 1990). Kandungan logam $\mathrm{Cu}$ total dalam tanah pertanian organik sebelum penanaman dan saat panen berada pada tingkat pencemaran tinggi, yaitu 75-200 ppm (Rosmarkam dan Yuwono, 2002).

Tabel 1. Kandungan Logam $\mathrm{Pb}$ dan $\mathrm{Cu}$ Total dalam Tanah Pertanian Organik

\begin{tabular}{ccccc}
\hline & \multicolumn{2}{c}{ TPO Sebelum Penanaman } & \multicolumn{2}{c}{ TPO Saat Panen } \\
\hline Lahan & $\mathrm{Pb}(\mathrm{mg} / \mathrm{kg})$ & $\mathrm{Cu}(\mathrm{mg} / \mathrm{kg})$ & $\mathrm{Pb}(\mathrm{mg} / \mathrm{kg})$ & $\mathrm{Cu}(\mathrm{mg} / \mathrm{kg})$ \\
\hline 1 & $746,1042 \pm 1,6269$ & $93,1281 \pm 1,4059$ & $277,7876 \pm 2,3697$ & $48,6088 \pm 2,3070$ \\
2 & $857,9188 \pm 2,2966$ & $114,3259 \pm 1,8487$ & $324,4459 \pm 2,1671$ & $92,3708 \pm 1,8463$ \\
3 & $897,3754 \pm 3,0006$ & $110,8850 \pm 2,0163$ & $328,8217 \pm 1,9301$ & $56,9175 \pm 2,2361$ \\
\hline
\end{tabular}

Kandungan logam $\mathrm{Pb}$ yang lebih tinggi dari $\mathrm{Cu}$ dipengaruhi oleh logam $\mathrm{Cu}$ yang terikat kuat pada senyawa organik sehingga mobilitasnya dalam tanah berkurang (Reichman, 2002). Kandungan logam $\mathrm{Pb}$ dan $\mathrm{Cu}$ dalam tanah sebelum penanaman lebih tinggi dibanding tanah saat panen menunjukkan sejumlah tertentu logam selama penanaman sayuran terserap ke dalam tanaman dan terakumulasi pada bagian tertentu tanaman atau terserap oleh organisme lain di tanah tersebut. Tingginya kandungan logam $\mathrm{Pb}$ dan $\mathrm{Cu}$ pada tanah pertanian organik dapat dipengaruhi oleh penggunaan pupuk yang mengandung logam berat, dan emisi gas buang dari kendaraan bermotor yang mengandung TEL dan TML. Mengingat Bedugul merupakan daerah pariwisata, seperti yang dilaporkan oleh Saputra (2013), bahwa tanah pertanian dekat jalan raya mengandung logam $\mathrm{Pb}$ hingga $14,6162 \mathrm{mg} / \mathrm{kg}$ lebih tinggi dari tanah yang jauh dari jalan raya.

\section{Spesiasi dan Bioavailabilitas $\mathrm{Pb}$ dan $\mathrm{Cu}$ dalam Tanah}

Penentuan spesiasi dan bioavailabilitas $\mathrm{Pb}$ dan $\mathrm{Cu}$ dalam tanah pertanian organik dilakukan dengan metode ekstraksi bertahap yang dikembangkan oleh Tessier et al. (1979) dengan membagi fraksi-fraksi dalam berbagai jenis ikatannya, yaitu fraksi EFLE (Easily, Freely, Leachable, and Exchangeable), fraksi $\mathrm{Fe} / \mathrm{Mn}$ oksida (Acid Reducible), fraksi organik dan sulfida (Oxidisable), dan fraksi resistant. Konsentrasi dan persentase logam $\mathrm{Pb}$ dan $\mathrm{Cu}$ terekstraksi dapat dilihat pada Tabel 2 dan 3.

Persentase logam dalam tanah pertanian sebelum penanaman dan saat panen yang terekstraksi pada fraksi EFLE berkisar antara $17,80-21,62 \%$ dan $6,19-12,07 \%$ untuk $\mathrm{Pb}$, serta $5,02-7,89 \%$ dan $3,05-8,13 \%$ untuk $\mathrm{Cu}$. Fraksi EFLE merupakan fraksi yang mobile mudah larut dalam air dan asam lemah, sangat labil, mudah terionisasi, cenderung berupa 
senyawa karbonat atau sebagai ion, mudah dipertukarkan tanpa melalui reaksi oksidasi reduksi seperti ikatan karbonat dan penukar ion. Persentase logam yang terekstrak pada fraksi $\mathrm{Fe} / \mathrm{Mn}$ oksida dari tanah pertanian sebelum penanaman dan saat panen berturutturut adalah 20,21-23\% dan 15,55-24,63\% untuk $\mathrm{Pb}$, dan untuk $\mathrm{Cu}$ sebesar 12,91-14,30\% dan 1,47-5,92\%. Fraksi Fe/Mn oksida merupakan fraksi yang menunjukkan logam yang terikat pada $\mathrm{Fe} / \mathrm{Mn}$ oksida yang dapat direduksi oleh asam.

Pada fraksi organik/sulfida, persentase logam terekstraksi dalam tanah pertanian sebelum penanaman dan saat panen sebesar 22,96-25,23\% dan 28,80-32,03\% untuk $\mathrm{Pb}$, sedangkan untuk $\mathrm{Cu}$ sebesar
$42,80-46,27 \%$ dan 40,67-56,07\%. Fraksi organik/sulfida menunjukkan logamlogam yang terikat kuat pada bahan organik/sulfida dapat terdegradasi apabila ada oksidator kuat dalam tanah tersebut. Persentase logam $\mathrm{Pb}$ dalam tanah pertanian sebelum penanaman yang terekstrak pada fraksi resistant berkisar antara 30,73-36,89\% dan 38,67-42,36\%, sedangkan untuk logam $\mathrm{Cu}$ sebesar 32,81$39,25 \%$ dan 39,41-47,64\%. Fraksi resistant merupakan fraksi yang mencakup logam yang bersifat stabil dan terikat kuat pada mineral-mineral dalam tanah (Gasparatos et al., 2005)

Tabel 2. Logam $\mathrm{Pb}$ dan $\mathrm{Cu}$ yang Terekstraksi dalam Tanah Pertanian Organik Sebelum Penanaman

\begin{tabular}{cccccc}
\hline \multirow{2}{*}{ Lahan } & \multirow{2}{*}{ Fraksi } & \multicolumn{2}{c}{ Konsentrasi $(\mathrm{mg} / \mathrm{kg})$} & \multicolumn{2}{c}{$\%$ Terekstraksi } \\
\cline { 3 - 6 } & & $\mathrm{Pb}$ & $\mathrm{Cu}$ & $\mathrm{Pb}$ & $\mathrm{Cu}$ \\
\hline \multirow{4}{*}{1} & EFLE & 161,4829 & 7,3789 & 21,61 & 7,89 \\
& Fe/Mn Oksida & 171,6739 & 12,4616 & 23,00 & 13,46 \\
& Organik/Sulfida & 183,7137 & 40,6766 & 24,65 & 43,60 \\
& Resistant & 229,2319 & 32,6109 & 30,73 & 35,06 \\
\hline \multirow{3}{*}{2} & EFLE & 152,7237 & 5,7419 & 17,80 & 5,02 \\
& Fe/Mn Oksida & 173,3798 & 14,7699 & 20,21 & 12,91 \\
& Organik/Sulfida & 216,7587 & 48,9277 & 25,23 & 42,82 \\
& Resistant & 315,0567 & 44,8914 & 36,76 & 39,25 \\
\hline \multirow{2}{*}{3} & EFLE & 171,2383 & 7,3203 & 19,04 & 6,61 \\
& Fe/Mn Oksida & 189,4109 & 15,8922 & 21,11 & 14,30 \\
& Organik/Sulfida & 205,8607 & 51,3482 & 22,96 & 46,27 \\
& Resistant & 330,8656 & 36,3243 & 36,89 & 32,81 \\
\hline
\end{tabular}

Tabel 3. Logam $\mathrm{Pb}$ dan $\mathrm{Cu}$ yang Terekstraksi dalam Tanah Pertanian Organik Saat Panen

\begin{tabular}{cccccc}
\hline \multirow{2}{*}{ Lahan } & \multirow{2}{*}{ Fraksi } & \multicolumn{2}{c}{ Konsentrasi $(\mathrm{mg} / \mathrm{kg})$} & \multicolumn{2}{c}{$\%$ Terekstraksi } \\
\cline { 3 - 6 } & & $\mathrm{Pb}$ & $\mathrm{Cu}$ & $\mathrm{Pb}$ & $\mathrm{Cu}$ \\
\cline { 3 - 6 } 1 & EFLE & 17,0729 & 3,9287 & 6,19 & 8,13 \\
& Fe/Mn Oksida & 58,3628 & 2,8487 & 21,01 & 5,92 \\
& Organik/Sulfida & 84,4424 & 19,8542 & 30,44 & 40,67 \\
& Resistant & 117,9094 & 21,9773 & 42,36 & 45,27 \\
\hline \multirow{4}{*}{2} & EFLE & 25,6441 & 2,8330 & 7,90 & 3,05 \\
& Fe/Mn Oksida & 79,9368 & 1,3483 & 24,63 & 1,47 \\
& Organik/Sulfida & 93,4260 & 52,0575 & 28,80 & 56,07 \\
& Resistant & 125,4390 & 36,1321 & 38,67 & 39,41 \\
\hline \multirow{2}{*}{3} & EFLE & 39,6897 & 3,7174 & 12,07 & 6,41 \\
& Fe/Mn Oksida & 51,1455 & 2,6677 & 15,55 & 4,60 \\
& Organik/Sulfida & 105,3428 & 23,6911 & 32,03 & 41,35 \\
& Resistant & 132,6617 & 26,8413 & 40,35 & 47,64 \\
\hline
\end{tabular}


Bioavailabilitas logam $\mathrm{Pb}$ dan $\mathrm{Cu}$ dalam tanah pertanian organik dapat diketahui dengan membandingkan konsentrasi logam yang terkstraksi pada setiap fraksi dengan konsentrasi logam berat total pada masingmasing lahan. Persentase logam yang terekstraksi pada fraksi EFLE merupakan logam yang langsung bioavailabel atau tersedia untuk hayati, fraksi Fe/Mn oksida dan fraksi organik/sulfida merupakan logam yang berpotensi bioavailabel, serta fraksi 4 atau fraksi resistant adalah logam yang non bioavilabel. Pada penelitian ini persentase logam $\mathrm{Pb}$ dan $\mathrm{Cu}$ yang langsung bioavailabel pada tanah pertanian organik sebelum penanaman berkisar $17,80-21,62 \%$ dan 5,02$7,89 \%$, sedangkan logam yang berpotensi bioavailabel sebesar 44,07-47,65\% dan 55,73$60,57 \%$. Persentase logam $\mathrm{Pb}$ dan $\mathrm{Cu}$ yang non bioavailabel adalah $30,73-36,89 \%$ dan 32,81$39,25 \%$.

Persentase logam $\mathrm{Pb}$ dan $\mathrm{Cu}$ yang berpotensi bioavailabel lebih tinggi mengindikasikan bahwa tanah pertanian mengandung $\mathrm{Fe} / \mathrm{Mn}$ oksida dan organik/sulfida yang relatif tinggi, dimana $\mathrm{Fe} / \mathrm{Mn}$ oksida dan organik/sulfida memegang peran penting dalam mengikat logam $\mathrm{Pb}$ sehingga menjadi kurang bioavailabel dalam keadaan normal. Bioavailabilitas logam $\mathrm{Cu}$ yang relatif rendah menujukkan bahwa tanaman yang tumbuh pada tanah pertanian tersebut kemungkinan tidak tercemar oleh $\mathrm{Cu}$, dan $\mathrm{Cu}$ merupakan unsur mikro yang diperlukan dalam metabolisme tumbuhan. Selain itu, $\mathrm{Cu}$ yang berpotensi bioavailabel akan sulit terdegradasi dan berubah menjadi spesies logam bebas yang bioavailabel, karena $\mathrm{Cu}$ memiliki afinitas yang kuat terhadap senyawa organik yang ada dalam tanah (Reichman, 2002).

\section{Konsentrasi Pb dan $\mathrm{Cu}$ Total Dalam Sampel Sayur Brokoli}

Edible part, yaitu bagian massa bunga (curd) yang berwarna hijau yang tersusun rapat dengan batang tebal. Kandungan $\mathrm{Pb}$ dan $\mathrm{Cu}$ total secara berturut-turut sebesar 27,2968$30,3621 \mathrm{mg} / \mathrm{kg}$ dan $27,0303-30,0223 \mathrm{mg} / \mathrm{kg}$. Hasil tersebut menunjukkan bahwa kandungan logam $\mathrm{Pb}$ yang terkandung dalam sayur brokoli dari tanah pertanian organik di daerah Bedugul sangat tinggi, dan telah melewati batas maksimum yang ditentukan oleh Badan Standarisasi Nasional Indonesia 7387:2009, yaitu $0,5 \mathrm{mg} / \mathrm{kg}$ untuk logam $\mathrm{Pb}$ dalam sayuran dan olahannya. Sementara itu, kandungan logam $\mathrm{Cu}$ masih berada di bawah ambang batas dan dalam kategori aman berdasarkan Surat Keputusan Direktur Jendral POM No.03725/B/SKVII/89 yang memperbolehkan kadar logam $\mathrm{Cu}$ dalam sayuran serta olahannya sebesar $50 \mathrm{mg} / \mathrm{kg}$.

Tabel 4. Kandungan $\mathrm{Pb}$ dan $\mathrm{Cu}$ dalam Sayur Brokoli

\begin{tabular}{ccc}
\hline Lahan & $\mathrm{Pb}(\mathrm{mg} / \mathrm{kg})$ & $\mathrm{Cu}(\mathrm{mg} / \mathrm{kg})$ \\
\hline 1 & $28,4776 \pm 1,0774$ & $27,8513 \pm 1,3595$ \\
2 & $30,3621 \pm 2,0971$ & $30,0223 \pm 2,0509$ \\
3 & $27,2968 \pm 1,8484$ & $27,0303 \pm 1,8326$ \\
\hline
\end{tabular}

Besarnya kandungan $\mathrm{Pb}$ dan $\mathrm{Cu}$ dalam edible part sayur brokoli dipengaruhi oleh kandungan logam yang mencemari tanah pertanian akibat penggunaan pupuk, dan emisi gas buang kendaraan bermotor yang mengandung TEL dan TML. Faktor lain yang mempengaruhi akumulasi logam berat dalam tanaman yaitu jangka waktu tanaman kontak dengan logam berat, jenis logam, spesies tanaman, komposisi tanah, kondisi geografis dan atmosfer, suhu dan $\mathrm{pH}$ tanah, bagian tanaman, mobilitas ion logam ke zona perakaran, pergerakan logam berat dari permukaan akar ke dalam akar tanaman dan pergerakan logam berat dalam jaringan tanaman lainnya (Radulescu et al., 2013; Alloway, 1990). Logam $\mathrm{Pb}$ merupakan logam non esensial yang keberadaannya dalam tubuh tidak dibutuhkan, dan bersifat toksik (Widowati dkk, 2008), karena keberadaannya dalam tubuh bersifat menghambat kerja enzim (Purnomo, 2007). Logam (Cu) merupakan logam esensial yang dibutuhkan oleh makhluk hidup dalam jumlah tertentu. Logam $\mathrm{Cu}$ diperlukan oleh berbagai sistem enzim dalam tubuh manusia, sehingga $\mathrm{Cu}$ harus selalu ada di dalam makanan. Logam $\mathrm{Cu}$ yang berlebihan dalam tubuh manusia akan menimbulkan efek toksik yang menyebabkan gangguan kesehatan, bahkan kematian (Purwiyanto, 2013). 


\section{SIMPULAN DAN SARAN}

\section{Simpulan}

Kandungan total logam $\mathrm{Pb}$ dan $\mathrm{Cu}$ secara berturut-turut adalah 746,1042-897,3754 $\mathrm{mg} / \mathrm{kg}$ dan $93,1281-114,3259 \mathrm{mg} / \mathrm{kg}$ dalam tanah pertanian organik sebelum penanaman, dan $277,7876-328,8217 \mathrm{mg} / \mathrm{kg}$ dan $48,6088-$ $92,3708 \mathrm{mg} / \mathrm{kg}$ dalam tanah pertanian organik saat panen, serta $27,2968-30,3621 \mathrm{mg} / \mathrm{kg}$ dan $27,0303-30,0223 \mathrm{mg} / \mathrm{kg}$ dalam sayur brokoli. Logam $\mathrm{Pb}$ dan $\mathrm{Cu}$ dalam tanah pertanian organik sebelum penanaman yang bioavailabel sebesar 17,80-21,62\% dan 5,02-7,89\%, sedangkan yang berpotensi bioavailabel sebesar 44,07-47,65\% dan 55,73-60,57\%, dan logam $\mathrm{Pb}$ dan $\mathrm{Cu}$ yang non bioavailabel sebesar 30,73-36,89\% dan 32,81-39,25\%. Selain itu, logam $\mathrm{Pb}$ dan $\mathrm{Cu}$ dalam tanah pertanian organik saat panen yang bioavailabel sebesar $\quad 6,19-12,07 \%$ dan 3,05-8,13\%, sementara yang berpotensi bioavailabel sebesar $47,58-53,43 \%$ dan 58,63-81,00\%, dan logam $\mathrm{Pb}$ dan $\mathrm{Cu}$ yang non bioavailabel adalah $38,67-42,36 \%$ dan $10,87-38,33 \%$.

\section{Saran}

Perlu dilakukan penelitian lebih lanjut mengenai akumulasi logam berat lainnya dalam tanah pertanian organik sehingga dapat diketahui tingkat pencemaran akibat logam berat serta hubungan antara bioavailabilitas logam dalam tanah dengan kandungan logam total dalam sayur brokoli yang ditanam di tanah pertanian tersebut serta menganalisis seluruh bagian sayur brokoli untuk mengetahui bagian tanaman tersebut yang mengakumulasi logam berat paling banyak.

\section{UCAPAN TERIMAKASIH}

Terimakasih penulis ucapkan kepada Bapak Mangku sebagai pemilik lahan yang telah mengizinkan lahan pertaniannya sebagai lokasi sampling, Bapak dan Ibu laboran di Laboratorium Bahan Pangan Fakultas Teknologi Pertanian, dan Laboratorium Fakultas Matematika dan Ilmu Pengetahan Alam Universitas Udayana yang telah membantu penelitian sehingga tulisan ini dapat terselesaikan.

\section{DAFTAR PUSTAKA}

Alloway, B.J. 1990 Heavy Metal in Soils. New York: Jhon Willey and Sons Inc.

Chan, C. C., Lam, H., Lee, Y. C., Zhang, X. 2004. Analytical Method Validation and Instrument Performance Verification. New Jersey: John Wiley \&Sons, Inc. Publication.

Charlena. 2004. Pencemaran Logam Berat Timbal $(\mathrm{Pb})$ dan Cadmium (Cd pada Sayur-sayuran, Falsafah Sains Program Pascasarjana S3 IPB, Bogor.

Davidson, C.M., Duncan, A.L., Littlejohn, D., Ure, A.M., Garden, L.M. 1998. Critical Evaluation of the Three-Stage

BCR Sequential Extraction Procedure to Assess the Potential Mobility and Toxicity of Heavy Metals in Industrially-Contaminated Land, Analytica Chimica Acta, 363(1): 45-55.

Direktur Jenderal Pengawasan Obat dan Makanan. 1989. Surat Keputusan Direktur Jenderal Pengawasan Obat dan Makanan No. 03725/B/SK/VII/89 tentang Batas Maksimum Cemaran Logam Dalam Makanan.

Gasparatos, D., Haidouti, C., Andrinopoulus and Areta, O. 2005. Chemical Speciation and Bioavailability of $\mathrm{Cu}$, $\mathrm{Zn}$, and $\mathrm{Pb}$ in Soil from The National Garden of Athens, Greece, Proceedings: International Conference on Environmental Science and Technology, Rhodes Island.

Oluremi, O.I., Ayodele, O.E., Olabisi, B.M., Wasiu, M.O. 2013. Speciation of Heavy Metal in Soil, and Their Phytoavailability in Edible Part of Amarantus hybridus Cultivated Along Major Roads in Ile-Ife Nigeria.

African Journal of Pure and Applied Chemistry. 7(5): 184-193

Purnomo, T., dan Muchyiddin. 2007. Analisis Kandungan Timbal $(\mathrm{Pb})$ pada Ikan Bandeng (Chanos chanos Forsk.) di Tambak Kecamatan Gresik. Neptunus. 14(1): 68-77. 
Purwiyanto, A. I. S. 2013. Daya Serap Akar dan Daun Mangrove Terhadap Logam Tembaga $(\mathrm{Cu})$ di Tanjung Api-Api, Sumatera Selatan. Maspari Journal. 5(1): 1-5

Radulescu, C., Stihi, C., Popescu, I. V., Dulama, I. D., Chelarescu, I. D., Chilian, A. 2013. Heavy Metal Accumulation and Translocation in Different Parts of Brassica oleracea. L. Romania Journal of Physic. 58(9): 1337-1354.

Reichman, S.M.. 2002. The Responses of Plants to Metal Toxicity: A Review Focusing on Copper, Manganese, and Zinc. The Australian Minerals \& Energy Environment Foundation, Australia

Rosmarkam, A., dan Yuwono, N.W. 2002. Ilmu Kesuburan Tanah. Kanisius. Yogyakarta

Saputra, I G. E., Siaka, I M., Diantariani, N. P. 2013. Total Logam $\mathrm{Pb}$ dan $\mathrm{Cr}$ dalam Tanah Pertanian dan Air

Danau Beratan serta

Bioavailabilitasnya dalam Tanah

Pertanian di Daerah Bedugul. Jurnal Kimia. 8(1): 28-34

Siaka, M., Owens, C. M., Birch, G. F. 2006.

Evaluation of Some Digestion Methods for the Determination of Heavy Metals in Sediment Samples by Flame-AAS. Analytical Letters. 31(4): 703-718

Widaningrum, Miskiyah, dan Suismono. 2007. Bahaya Kontaminasi Logam Berat dalam Sayuran dan Alternatif Pencegahan Cemarannya, Balai Besar Penelitian dan Pengembangan Pascapanen Pertanian. Buletin Teknologi Pascapanen Pertanian. 3: 16-27

Widowati, W., Sastiono. A., Raymond, R., J. 2008. Efek Toksik Logam, Yogyakarta: Penerbit Andi. 